\title{
Molecular Serotyping and Antibiotic Resistance Patterns of Escherichia coli Isolated in Hospital Catering Service in Morocco
}

\author{
Benjelloun Touimi Ghita, ${ }^{1,2}$ Laila Bennani, ${ }^{1,3}$ Sanae Berrada, ${ }^{3}$ Moussa Benboubker, \\ and Bahia Bennani $\mathbb{D D}^{1}$ \\ ${ }^{1}$ Laboratory of Human Pathology Biomedicine and Environment, Faculty of Medicine and Pharmacy of Fez (FMPF), \\ Sidi Mohammed Ben Abdellah University (USMBA), Fez, Morocco \\ ${ }^{2}$ Faculty of Sciences and Techniques of Fez (FSTF), USMBA, Fez, Morocco \\ ${ }^{3}$ The Superior Institute of Nursing Professions and Health Technology of Fez (ISPITS), Fez, Morocco \\ ${ }^{4}$ Nursing Department, Hassan II University Hospital, Fez, Morocco \\ Correspondence should be addressed to Bahia Bennani; bahia.bennani@usmba.ac.ma
}

Received 12 January 2020; Accepted 31 July 2020; Published 19 August 2020

Academic Editor: Todd R. Callaway

Copyright (c) 2020 Benjelloun Touimi Ghita et al. This is an open access article distributed under the Creative Commons Attribution License, which permits unrestricted use, distribution, and reproduction in any medium, provided the original work is properly cited.

\begin{abstract}
Escherichia coli is related to foodborne disease and outbreaks worldwide. It mainly affects persons at high risk as newborns, infants, and individuals with impaired immune system in hospitals. Multidrug-resistant $E$. coli is currently spreading both in community and hospital settings. Our study aims to evaluate the presence of $E$. coli and the incidence of its antibiotic resistance in samples obtained from various cooked and raw foods $(N=300)$, food contact surfaces $(N=238)$, and food handlers $(N=40)$ in Moroccan hospital catering service. E. coli was identified using API 20E, and the antibiotic resistance patterns were obtained using the agar disk diffusion methods. However, PCR method was used for O157 and H7 typing. The samples analysis showed that $14.33 \%, 24.16 \%$, and $45 \%$ of food, surfaces, and food handlers harbored E. coli, respectively, with the highest rates obtained in raw meats $(34.88 \%)$ and salads $(34.88 \%)$. Molecular amplification shows that $14 \mathrm{E}$. coli isolates carried the flagellar antigen $\mathrm{H} 7$, while there are no isolates showing amplification for O157. The high rate of resistance was noted against ampicillin (100\%), amoxicillinclavulanate acid (100\%), nalidixic acid (61.62\%), and cefotaxime (59.49\%), and isolates obtained from food handler's hands showed the highest rates of resistance. None of the isolates are extended-spectrum beta-lactamases producing, while $27.7 \%$ of the isolates were metallo-beta-lactams producing. This first study conducted on Moroccan hospital catering services may draw the authorities' attention to the necessity of setting up a surveillance system to monitor the food preparation process and the safety of prepared food in healthcare settings.
\end{abstract}

\section{Introduction}

Escherichia coli (E. coli) is facultative anaerobic, non-spore forming, Gram-negative bacteria within the Enterobacteriaceae family. It forms part of the humans and warmblooded animals natural gastrointestinal flora $[1,2]$. Although most E. coli are harmless commensal organisms [3], several pathogenic strains can cause a variety of diseases. There are six pathogenic groups with different virulence traits and mechanisms of pathogenicity [4]. Diarrheagenic E. coli $\mathrm{O} 157: \mathrm{H7}$ is a common serotype [5] and the main cause of foodborne disease and outbreaks worldwide. It represents a risk to global food safety and public health [6] primarily for persons at high risk as newborns, infants, and individuals with compromised immune system [2].

Besides their pathogenesis and virulence, E. coli strains also acquire resistance over time. Mobile DNA elements, temperate bacteriophage, and transmissible plasmid have all served as carriers for antibiotic resistance genes in E. coli [7]. In fact, E. coli belongs to the group I enterobacteria, characterized by a phenotype naturally sensitive to all $\beta$-lactams. It is also naturally sensitive to other classes of antibiotics 
including aminoglycosides, quinolones, sulfonamides, trimethoprim, tetracycline, and chloramphenicol. However, this bacterium is a good example of antibiotic resistance evolution, and multidrug-resistant (MDR) strains are currently spreading in both community and hospital settings [8]. Due to their ubiquity and infections frequency, the spread of MDR E. coli is of great concern to the medical community [7]. Therefore, MDR bacteria contaminated food could be a serious threat to consumer health especially to vulnerable patients in hospitals $[9,10]$ who are highly disposed to infection due to their illness, treatment, or their compromised immune system [7, 11]. Hence, several epidemiological studies have shown the correlation between increased morbidity and mortality with resistant foodborne pathogens infections $[12,13]$. Thus, nosocomial foodborne infections prevention is essential, and implementing a surveillance system in healthcare setting is required.

There are few data on the prevalence and antimicrobial resistance of $E$. coli in food, food surfaces, and food handlers in Morocco. This is the first study that evaluates the presence of E. coli and O157:H7 serotype and determines their antibiotics resistance in a Moroccan hospital kitchen environment (food, food contact surfaces, and food handlers (hand carriage)).

\section{Materials and Methods}

2.1. Study Design. This study was conducted in a hospital food service in Morocco that produces more than 1000 meals per day to serve patients and medical staff. E. coli detection was performed on food, food contact surfaces, utensils, and hand samples among food handlers.

2.2. Sample Collection. A total of 608 samples were collected from May 2015 till June 2016. They were 300 food samples, 238 surfaces and utensils samples, and 40 hand samples. Food samples were collected aseptically using sterile spoons and placed into Stomacher bags (Grade, UK). The targeted surfaces and an area ranging from 20 to $100 \mathrm{~cm}^{2}$ (according to the dimension of the surface to be sampled) were swabbed by sterile cotton swabs (Oxoid, UK), premoistened into a $2 \mathrm{~mL}$ sterile Brain heart Infusion solution (Oxoid, UK) then transported to the laboratory in ice boxes $\left(4^{\circ} \mathrm{C}\right)$ [14]. The biological samples were collected from bare-hand food handlers using swabs as recommended by Evancho et al. [15]. All samples were obtained during the food preparation process.

2.3. E. coli Isolation and Identification. Twenty-five grams of each samples was homogenized with $225 \mathrm{~mL}$ of sterilized peptone water. $1 \mathrm{~mL}$ aliquots of the homogenate was inoculated into $15 \mathrm{~mL}$ of Violet Red Bile Lactose Agar (Biokar Diagnostics, France) then incubated for $24 \mathrm{~h}$ at $37^{\circ} \mathrm{C}$. The presumptive colonies were streaked into eosin methylene blue agar (Biokar Diagnostics, France). E. coli identification was based on morphological, microscopic characteristics and biochemical assays, including gram straining, oxidase, indole, fermentation, citrate degradation, then confirmed by API 20E kit (BioMerieux, France).

2.4. Molecular Detection of fliCH7 and rbfO157 Genes in the Isolated Strains. Molecular serotyping was performed on all E. coli isolates using PCR to detect the serogroup O157 and the $\mathrm{H} 7$ antigen (Table 1). The obtained PCR products were sequenced using an ABI PRISM 3130DNA Analyzer and the data were processed with the Sequencing Analysis 3.3 software (Applied Biosystems).

2.5. Antimicrobial Susceptibility Testing. Antimicrobial susceptibility was determined using disk diffusion method on Muller-Hinton agar (Biokar Diagnostics, France) and interpreted according to the European Committee on Antimicrobial Susceptibility recommendations [18]. The tested antibiotics (Oxoid, UK) were ceftazidime $(30 \mu \mathrm{g})$, cefotaxime $(30 \mu \mathrm{g})$, trimethoprim-sulfamethoxazole $(25 \mu \mathrm{g})$, gentamicin $(30 \mu \mathrm{g})$, ciprofloxacin $(30 \mu \mathrm{g})$, amikacin $(30 \mu \mathrm{g})$, ampicillin $(10 \mu \mathrm{g})$, amoxicillin-clavulanic acid $(20 / 10 \mu \mathrm{g})$, and imipenem $(10 \mu \mathrm{g})$.

2.6. Phenotypic Detection of Extended-Spectrum Beta-Lactamases (ESBL) and Metallo-Beta-Lactamases (MBL). ESBL presence was checked by double-disk synergy test. It was performed on agar with $30 \mu \mathrm{g}$ disk of cefotaxime, ceftazidime and a disk of amoxicillin-clavulanate $(20 \mu \mathrm{g} / 10 \mu \mathrm{g})$ positioned at a distance of $30 \mathrm{~mm}$. The test was considered positive when a decreased susceptibility to cefotaxime combined with a clear-cut enhancement of the inhibition zone in front of the clavulanate-containing disk was observed [19].

EDTA disk synergy test was used to detect metallo-betalactamases (MBL) activity. A suspension of E. coli $(0.5$ McFarland) was swabbed over Mueller-Hinton agar (Biokar Diagnostics, France) surface. After drying, an imipenem disk $(10 \mu \mathrm{g})($ Oxoid, UK) and a blank filter paper disk were placed $10 \mathrm{~mm}$ apart from edge to edge; then $10 \mu \mathrm{L}$ of $0.5 \mathrm{M}$ EDTA solution was added to the blank disk. After overnight incubation, the presence of an expanded inhibition zone was interpreted as EDTA synergy test positive [20].

\section{Results}

3.1. E. coli Prevalence. The samples' bacteriological analysis shows that $14.33 \%$ of food samples harbored E. coli (Table 2). The highest rates were isolated in raw meats $(34.88 \%)$ and salads $(34.88 \%)$, while the lowest rates were obtained in the hot meals (9.31\%) and pastries. Regarding the utensils and food contact surfaces, the raw meats worktops were the most contaminated with a rate of $59.09 \%$, whereas the pastries worktops were exempts from E. coli. However, E. coli was detected in $45 \%$ of the examined food handler's samples.

3.2. E. coli O157 H7 Molecular Serotyping. Molecular amplification shows that $14 \mathrm{E}$. coli isolates carried the flagellar antigen H7. However, no isolates show amplification for O157. Thus, haemorrhagic E. coli O157:H7 was not detected in any of the examined samples (Table 3). 
TABLe 1: Primers used for the detection of $f l i c H 7$ and $r f b O 157$ genes.

\begin{tabular}{lcccc}
\hline Amplified regions & Primers & Sequences $\left(5^{\prime}-3^{\prime}\right)$ & Size $($ Pb) & Reference \\
\hline \multirow{2}{*}{$f l i C H 7$} & Flic F & FGCGCTGTCGAGTTCTATCGAGC & 625 & {$[16]$} \\
\hline \multirow{2}{*}{$r f b 0157$} & Flic R & CAACGGTGACTTTATCGCCATTCC & \multirow{2}{*}{256} & {$[17]$} \\
\hline
\end{tabular}

TABLE 2: Prevalence of $E$. coli according to samples types.

\begin{tabular}{lcc}
\hline Samples & Samples collected $(N)$ & Positive samples $N(\%)$ \\
\hline Food samples & 39 & $15(34.88)$ \\
Raw meats & 33 & $7(16.27)$ \\
Raw vegetables & 150 & $4(9.31)$ \\
Hot meals & 54 & $15(34.88)$ \\
Salads & 24 & $2(4.66)$ \\
Pastries & 300 & $43(14.33)$ \\
Total & & $12(46.15)$ \\
Surfaces and utensils & 26 & $2(2)$ \\
Chopping meat devise & 10 & $2(12.5)$ \\
Knives & 16 & $8(20)$ \\
Weighing machine & 20 & $3(7.89)$ \\
Sink & 38 & 0 \\
Recipient & 30 & $1(3.33)$ \\
Baking stainless steel worktop & 30 & $26(59.09)$ \\
Serving meals worktop & 44 & $4(16.66)$ \\
Raw meat cutting boards & 24 & $58(24.16)$ \\
Vegetables cutting boards & 238 & $18(45)$ \\
Total & 40 & \\
\hline Hand carriage & & \\
\hline
\end{tabular}

TABLe 3: Molecular serotyping results of E. coli.

\begin{tabular}{lcc}
\hline & \multicolumn{2}{c}{$N(\%)$} \\
Samples & $f l i C H 7$ & rfbO157 \\
\hline Food $(n=300)$ & $9(3)$ & \\
Food contact surfaces $(n=208)$ & $3(1.25)$ & ND \\
Hand carriage $(n=40)$ & $2(5)$ & \\
\hline Total & $14(2.41 \%)$ & \\
\hline
\end{tabular}

3.3. Antibiotic and Resistance Profiles of Isolated Strains. Overall, the highest resistance rates were shown against ampicillin and amoxicillin-clavulanate acid (100\%), nalidixic acid (61.62\%), and cefotaxime (59.49\%). As reported in Table 4, the isolates obtained from food handler's hands showed the highest numbers of resistance among all the other strains. From food and food contact surfaces samples, the highest rates of resistance were observed in isolates obtained from raw meats and sinks, respectively. The ESBLproducing $E$. coli detection was performed on isolates with decreased resistance to third-generation cephalosporins. The results show that none of the tested isolates produced an extended-spectrum $\beta$-lactamase (ESBL). However, $27.7 \%$ of the isolates were carbapenemase producing (MBL).

As reported in Table 5, the E. coli isolated strains show a high resistance to the most tested antibiotics. A total of 44 multiresistance profiles were determined. For food samples, 28 profiles were determined with a predominance of the profile “AMC. AMP. CN. SXT. NA. IPM. CAZ" resistants, while the food contact surfaces harbored 7 profiles with a predominance of the profile "AMC. AMP. CN. SXT. NA. IPM. CAZ. CFM” resistants. Additionally, 28 profiles were detected in the staff hands with a predominance of the profile "AMC. AMP. CN. SXT. NA. IPM. CAZ. CFM" resistants.

\section{Discussion}

E. coli is foodborne pathogen identified in food products, human, and environmental samples worldwide [2, 21]. Several studies showed and documented an increase in its drug resistance during the last decades [22-24]. The aim of the present study is to provide an informative basis on the E. coli prevalence and its antibiotic resistance profiles in food (raw and cooked), food contact surfaces and its carriage among food handlers in hospital catering service in Morocco. As far as we know, the present investigation is the first one conducted on a hospital catering service in this country.

The microbiological analysis demonstrated that $14.33 \%$ of food samples harbored E. coli. This rate is higher than the one found in Iranian hospital (6.71\%) [10]. This high prevalence could be related to the long-process food production, the inadequate washing of raw materials, inadequate cooking process, and the nonrespect of the freezing/ cooling temperatures $[9,10]$.

The highest rates of $E$. coli were detected in raw meats (34.88\%) and salads (34.88\%) compared to hot meals (9.31\%) and pastries (4.66\%). A similar tendency was 
Table 4: Prevalence of antibiotic resistance.

\begin{tabular}{|c|c|c|c|c|c|c|c|c|c|c|c|c|}
\hline & \multirow{2}{*}{ Samples } & \multicolumn{8}{|c|}{ Prevalence of phenotypic resistance (\%) } & \multicolumn{2}{|c|}{ MBL } & \multirow{2}{*}{ ESBL } \\
\hline & & AMP & AMC & $\mathrm{CN}$ & SXT & NA & IPM & CAZ & CFM & $\mathrm{P}$ & $\mathrm{N}$ & \\
\hline \multirow{5}{*}{ Food samples } & Raw meats & 100 & 100 & 53.3 & 46.7 & 53.3 & 60 & 53.3 & 60 & 33.3 & 66.7 & ND \\
\hline & Raw vegetables & 100 & 100 & 42.9 & 42.9 & 85.7 & 14.3 & 57.1 & 57.1 & \multicolumn{2}{|c|}{ ND } & ND \\
\hline & Hot meals & 100 & 100 & 75 & 25 & 50 & 75 & 50 & 75 & 25 & 75 & ND \\
\hline & Salads & 100 & 100 & 46.7 & 66.7 & 60 & 46.7 & 46.7 & 40 & 20 & 80 & ND \\
\hline & Pastries & 100 & 100 & 50 & 0 & 100 & 100 & 0 & 50 & \multicolumn{2}{|c|}{ ND } & ND \\
\hline \multirow{9}{*}{ Food contact surfaces } & Chopping meat devise & 100 & 100 & 58.3 & 50 & 50 & 58.3 & 50 & 50 & 25 & 75 & ND \\
\hline & Knives & 100 & 100 & 100 & 50 & 50 & 50 & 100 & 100 & \multicolumn{2}{|c|}{ ND } & ND \\
\hline & Weighing machine & 100 & 100 & 0 & 0 & 0 & 0 & 50 & 50 & \multicolumn{2}{|c|}{ ND } & ND \\
\hline & Sink & 100 & 100 & 100 & 0 & 71.4 & 85.7 & 57.7 & 71.4 & 28.6 & 71.4 & ND \\
\hline & Recipient & 100 & 100 & 0 & 100 & 100 & 100 & 33.3 & 50 & \multicolumn{2}{|c|}{ ND } & ND \\
\hline & Baking worktops & 100 & 100 & 0 & 0 & 0 & 0 & 0 & 0 & \multicolumn{2}{|c|}{ ND } & ND \\
\hline & Serving meals worktops & 100 & 100 & 50 & 50 & 50 & 75 & 50 & 100 & \multicolumn{2}{|c|}{ ND } & ND \\
\hline & Raw meat cutting boards & 100 & 100 & 69.2 & 46.2 & 65.4 & 50 & 50 & 50 & 23.1 & 96.1 & ND \\
\hline & Vegetables cutting boards & 100 & 100 & 50 & 50 & 100 & 50 & 50 & 50 & \multicolumn{2}{|c|}{ ND } & ND \\
\hline \multirow{2}{*}{\multicolumn{2}{|c|}{$\begin{array}{l}\text { Hand carriage } \\
\text { Total }\end{array}$}} & 100 & 100 & 100 & 55.6 & 88.9 & 77.8 & 94.4 & 88.9 & 38.9 & 61.1 & ND \\
\hline & & 100 & 100 & 100 & 35.54 & 61.62 & 51 & 49.5 & 59.49 & 27.7 & 72.3 & ND \\
\hline
\end{tabular}

ATB: antibiotic; ND: not detected; P: positive; N: negative; AMP: ampicillin; CN: gentamicin; SXT: trimethoprim-sulfamethoxazole; NA: nalidixic acid; IPM: imipenem; CAZ: ceftazidime; CFM: cefotaxime; MBL: metallo-beta-lactamases; and ESBL: extended-spectrum beta-lactamases.

reported in an Iranian study with rates of $20 \%$ and $6 \%$ in raw meats and cooked meals, respectively [10]. The high rates of raw meats harboring $E$. coli could be related to one or multiple factors: (i) the meats autocontamination during slaughter as $E$. coli is a normal part of the intestinal microflora of many animals; (ii) the inadequate hygienic conditions in slaughterhouses; (iii) the inappropriate storage temperature specially that meat is a favorable medium to rapid development of bacteria $[25,26]$.

The high rates of $E$. coli in salads and raw vegetables can be related to an enteric contamination before product harvesting, a nonhygienic handling process and/or a contamination during the distribution process [27].

Regarding the utensils and food contact surfaces, the raw meats cutting boards were the most contaminated with a rate of $59.09 \%$. This rate is still lower than that reported in a Brazilian hospital (90\%) [28]. In fact, several studies demonstrated that these utensils present high microbial counts due to cross-contamination [29] and are influenced by the raw nature of handled materials and the surface material type (wood, stainless steel, plastic, etc.). Hence, the presence of $E$. coli in most food surfaces can be attributed to crosscontamination between food materials and these food contact surfaces and the subsequent growth of microorganisms in biofilms $[30,31]$. In fact, bacteria as $E$. coli have a strong capacity of forming biofilms which are characterized by their high resistance to antibiotics and to environmental stresses [32]. Klontz et al. described that $25 \%$ of food workers reported to reutilize cutting boards without cleaning after cutting raw chicken [33]. So, the lack of adequate food safety knowledge among food handlers [3] and the inadequate food contact surfaces cleaning and sanitizing as well as the overall sanitary conditions of food preparation in this facility can endorse the accumulation of food debris and bacteria in biofilms on surfaces.

The E. coli carriage among food handlers was observed in $45 \%$ of cases. Our result is similar to that of an Egyptian investigation reporting that $41 \%$ of food workers were carrying E. coli in their hands [34] but higher than the rates found in Malaysia (14.20\%) [35]. The food service employees' hands are considered as vectors of foodborne disease spread, mainly because of poor personal hygiene. In fact, it was proved that inappropriate food handler practices contributed to approximately $97 \%$ of foodborne illnesses in food service establishments [36]. Thus, hand washing is a fundamental precautionary measure to protect against the infection spread and is one of the primary practices for reducing the bacteria transfer [37-39].

In the present study, haemorrhagic E. coli O157:H7 has not been detected; $\mathrm{H} 7+$ non-O157 strains were isolated with a low rate $(2.41 \%)$. This result is similar to those reported in Moroccan study conducted on several food types (5\%) [40]. However, E. coli non-O157 have more recently been recognized as important pathogens with an increasing impact on human health and are now also considered as major cause of disease [41]. Its virulence, arises from Shiga (Vero) toxins-production coded by Shiga toxin genes (stx1 and stx2), which are the primary factor responsible for the haemorrhagic aspect of the diarrhea and systemic complications [42]. In this study, and in spite of the limitation related to the nondetermination of Shiga toxin genes presence, the detection of E. coli non-O157 in the food designated to vulnerable patients constitutes a high risk. The systematic detection of this species must be recommended routinely in this setting.

Moreover, E. coli antibiotic resistance is a topic that is continuously reviewed, and multiple studies are published every year with new data on antimicrobial resistance genes acquisition. Even if the emergence of new strains capable of hydrolyzing new generation of cephalosporins and $\beta$-lactams is common among $E$. coli isolated from foods [21, 22], the antibiotic resistance of strains isolated in hospital food have not been studied widely. 
Table 5: Antibiotic resistance profiles detected in E. coli.

\begin{tabular}{|c|c|c|c|c|c|}
\hline & & & & $N(\%)$ & \\
\hline & & Prome & Food & Food contact surfaces & Hand carriage \\
\hline 2 ATB & 1 & AMC. AMP & $-*$ & - & $2(3.4)$ \\
\hline & 2 & AMC. AMP. CN & - & $1(5.6)$ & - \\
\hline & 3 & AMC. AMP. NA & - & - & $1(1.7)$ \\
\hline & 4 & AMC. AMP. SXT & $1(2.3)$ & - & - \\
\hline 3 АПВ & 5 & AMC. AMP. IPM & $2(4.7)$ & - & $1(1.7)$ \\
\hline & 6 & AMC. AMP. CAZ & - & - & $4(6.9)$ \\
\hline & 7 & AMC. AMP. CFM & - & - & $3(5.2)$ \\
\hline & 8 & AMC. AMP. CN. NA & $1(2.3)$ & - & - \\
\hline & 9 & AMC. AMP. NA. IPM & $1(2.3)$ & - & - \\
\hline & 10 & AMC. AMP. NA. CAZ & - & - & $1(1.7)$ \\
\hline 4 АТВ & 11 & AMC. AMP. IPM. CAZ & $1(2.3)$ & - & - \\
\hline & 12 & AMC. AMP. IPM. CFM & - & - & $1(1.7)$ \\
\hline & 13 & AMC. AMP. CAZ. CFM & $3(7)$ & - & $3(5.2)$ \\
\hline & 14 & AMC. AMP. CN. SXT. NA & $1(2.3)$ & - & $3(5.2)$ \\
\hline & 15 & AMC. AMP. CN. NA. IPM & $1(2.3)$ & - & - \\
\hline & 16 & AMC. AMP. CN. NA. CAZ & $2(4.7)$ & - & - \\
\hline & 17 & AMC. AMP. CN. SXT. IPM & $2(4.7)$ & - & $1(1.7)$ \\
\hline & 18 & AMC. AMP. SXT. NA. IPM & - & - & $1(1.7)$ \\
\hline & 19 & AMC. AMP. CN. SXT. CFM & $3(7)$ & - & - \\
\hline 5 АТВ & 20 & AMC. AMP. CN. IPM. CFM & - & - & $1(1.7)$ \\
\hline & 21 & AMC. AMP. CN. CAZ. CFM & $2(4.7)$ & - & $4(6.9)$ \\
\hline & 22 & AMC. AMP. NA. CAZ. CFM & $1(2.3)$ & - & - \\
\hline & 23 & AMC. AMP. NA. IPM. CFM & $1(2.3)$ & - & - \\
\hline & 24 & AMC. AMP. SXT. NA. CFM & $2(4.7)$ & - & - \\
\hline & 25 & AMC. AMP. IPM. CAZ. CFM & - & $1(5.6)$ & $1(1.7)$ \\
\hline & 26 & AMC. AMP. CN. NA. CAZ. CFM & - & $1(5.6)$ & - \\
\hline & 27 & AMC. AMP. CN. NA. IPM. CAZ & - & $1(5.6)$ & $3(5.2)$ \\
\hline & 28 & AMC. AMP. CN. NA. IPM. CFM & $1(2.3)$ & - & $3(5.2)$ \\
\hline & 29 & AMC. AMP. CN. SXT. NA. IPM & $2(4.7)$ & - & $3(5.2)$ \\
\hline & 30 & AMC. AMP. CN. SXT. NA. CAZ & $1(2.3)$ & - & $1(1.7)$ \\
\hline & 31 & AMC. AMP. CN. SXT. NA. CFM & $1(2.3)$ & - & $2(3.4)$ \\
\hline 6 АТВ & 32 & AMC. AMP. CN. SXT. IPM. CAZ & - & - & $1(1.7)$ \\
\hline & 33 & AMC. AMP. SXT. NA. IPM. CFM & $2(4.7)$ & - & - \\
\hline & 34 & AMC. AMP. NA. IPM. CAZ. CFM & $2(4.7)$ & - & - \\
\hline & 35 & AMC. AMP. CN. IPM. CAZ. CFM & $1(2.3)$ & - & - \\
\hline & 36 & AMC. AMP. SXT. NA. CAZ. CFM & $1(2.3)$ & $1(5.6)$ & - \\
\hline & 37 & AMC. AMP. SXT. IPM. CAZ. CFM & $1(2.3)$ & - & - \\
\hline & 38 & AMC. AMP. CN. SXT. NA. IPM. CAZ & $4(9.3)$ & - & $3(5.2)$ \\
\hline & 39 & AMC. AMP. CN. SXT. NA. IPM. CFM & $1(2.3)$ & - & $1(1.7)$ \\
\hline & 40 & AMC. AMP. CN. NA. IPM. CAZ. CFM & - & $3(16.7)$ & $1(1.7)$ \\
\hline 7АТВ & 41 & AMC. AMP. CN. SXT. NA. CAZ. CFM & $1(2.3)$ & - & $2(3.4)$ \\
\hline & 42 & AMC. AMP. CN. SXT. IPM. CAZ. CFM & - & - & $1(1.7)$ \\
\hline & 43 & AMC. AMP. SXT. NA. IPM. CAZ. CFM & $1(2.3)$ & $1(5.6)$ & $2(3.4)$ \\
\hline 8 ATB & 44 & AMC. AMP. CN. SXT. NA. IPM. CAZ. CFM & - & $9(50)$ & $8(13.8)$ \\
\hline
\end{tabular}

$-^{*}$ : absent; AMP: ampicillin; CN: gentamicin; SXT: trimethoprim-sulfamethoxazole; NA: nalidixic acid; IPM: imipenem; CAZ: ceftazidime; and CFM: cefotaxime.

In this investigation, all isolates were resistant to ampicillin and amoxicillin and highest rates of resistance were obtained against nalidixic acid (61.62\%) and cefotaxime (59.49\%). These rates are consistent with those reported by Ranjbar et al. in E. coli isolated from hospital food $[9,10]$. In fact, isolates obtained from raw meats showed the highest rates of resistance to the tested antibiotics among all food sample types. This result was not surprising since a previous study conducted in Morocco shows that raw chicken harbored a high resistance against amoxicillin (90.9\%) [43]. Such resistance can be related to the use of these antibiotics in livestock either as therapeutic or preventive molecules. In fact, for economic reasons, the use of those antibacterial growth promoters is permitted and leads to an increase of antimicrobial resistance risks. Knowing that E. coli had high ability to exchange genetic material, the use of tetracycline and ampicillin in livestock (as is the case in Morocco) helps to resist spread [44, 45].

The isolates obtained from food handler's hands showed the highest rates of resistance among all the other isolates. This result corroborates the results of studies concluding that human isolates are more resistant than food isolates [46]. Effectively, a study conducted in Qatar showed that 59\% of 
healthy food handlers carried resistant E. coli in their hands and $27 \%$ were MDR [47]. The fact that healthy food handlers carry MDR E. coli represents an important public health risk to the general population because of the possibility of dissemination through contaminated food [47].

Independently of samples types, E. coli isolates show a resistance against the most tested antibiotics, and a total of 43 multiresistance profiles were determined. The profile showing resistance to "AMC, AMP, CN, SXT, NA, IPM, CAZ, CFM" was the most detected. The presence of this pattern can be explained by the large use of betalactams and cephalosporins as routine growth factors in veterinary and also as drugs of choice against E. coli in medicine [48-50].

None of the studied isolates produced an ESBL, while a large number of worldwide studies reported their important rate isolation especially from food-producing animals as chicken, beef, pork, and milk [21, 22, 51-53]. The ESBL absence is a positive point since the food is essentially destined to immunedepressed patients. Nevertheless, $27.7 \%$ of the E. coli isolates were carbapenemase-producing. Hence, the emergence of this isolates type in food or in the environment is worrying and an important concern for the public health sector specially that cephalosporins as "critically important" antimicrobials given that they represent the last treatment choice in human medicine for MDR bacterial infections [54, 55].

In conclusion, the present investigation is the first report on the prevalence and antibiotic resistance profiles of $E$. coli isolates obtained from food samples, food contact surfaces, and food handlers in hospital catering service in Morocco. The E. coli contamination was important with a high prevalence of MDR strains and the presence of E. coli non-O157/ $/ 7^{+}$. All E. coli isolates were resistant to at least 2 antibiotics (AMC and AMP). The obtained results highlight the need for continuous monitoring of the production chain and assessment of the implemented cleaning and sanitizing processes in order to minimize public-health risks. This study may draw the concerned authorities' attention to control the transmission of multiresistant foodborne pathogens mainly in healthcare settings.

\section{Data Availability}

All the data used in this study are included within the article.

\section{Conflicts of Interest}

The authors declare that they have no conflicts of interest regarding the publication of this paper.

\section{Acknowledgments}

The authors would like to express their deep gratitude to the hospital kitchen staff for participating in this study.

\section{References}

[1] M. S. Donnenberg, Escherichia coli: Pathotypes and Principles of Pathogenesis, Elsevier/Academic Press, Cambridge, MA, USA, 2013.
[2] M. Aijuka and E. M. Buys, "Persistence of foodborne diarrheagenic Escherichia coli in the agricultural and food production environment: implications for food safety and public health," Food Microbiology, vol. 82, pp. 363-370, 2019.

[3] K. Zerabruk, N. Retta, D. Muleta, and A. T. Tefera, "Assessment of microbiological safety and quality of minced meat and meat contact surfaces in selected butcher shops of Addis Ababa, Ethiopia," Journal of Food Quality, vol. 2019, Article ID 3902690, 2019.

[4] M. R. Adams and Y. Motarjemi, Emerging Foodborne Pathogens, Woodhead Publishing, Cambridge, UK, 2006, https://www.sciencedirect.com/book/9781855739635/ emerging-foodborne-pathogens.

[5] L. Beneduce, G. Spano, A. Q. Nabi et al., "Occurrence and characterization of Escherichia coli $\mathrm{O} 157$ and other serotypes in raw meat products in Morocco," Journal of Food Protection, vol. 71, no. 10, pp. 2082-2086, 2008.

[6] M. Aijuka, A. E. Santiago, J. A. Girón, J. P. Nataro, and E. M. Buys, "Enteroaggregative Escherichia coli is the predominant diarrheagenic E. coli pathotype among irrigation water and food sources in South Africa," International Journal of Food Microbiology, vol. 278, pp. 44-51, 2018.

[7] C.-Y. Chen, X. Yan, and C. R. Jackson, Antimicrobial Resistance and Food Safety: Methods and Techniques, Academic Press/ Elsevier, Cambridge, MA, USA, 1st edition, 2015.

[8] J. P. Horcajada, E. Shaw, B. Padilla et al., "Healthcare-associated, community-acquired and hospital-acquired bacteraemic urinary tract infections in hospitalized patients: a prospective multicentre cohort study in the era of antimicrobial resistance," Clinical Microbiology and Infection, vol. 19, no. 10, pp. 962-968, 2013.

[9] R. Ranjbar, A. Seif, and F. S. Dehkordi, "Prevalence of antibiotic resistance and distribution of virulence factors in the shiga toxigenic Escherichia coli recovered from hospital food," Jundishapur Journal of Microbiology, vol. 12, no. 5, 2019.

[10] R. Ranjbar, M. Masoudimanesh, F. S. Dehkordi, N. JonaidiJafari, and E. Rahimi, "Shiga (Vero)-toxin producing Escherichia coli isolated from the hospital foods virulence factors, o-serogroups and antimicrobial resistance properties," Antimicrobial Resistance \& Infection Control, vol. 6, no. 1, 2017.

[11] B. M. Lund and P. R. Hunter, The Microbiological Safety of Food in Healthcare Settings, Blackwell Publishing Ltd., Hoboken, NJ, USA, 2008, http://www.scopus.com/inward/ record.url? eid=2-s2.0-77953095870\&partnerID=40\&md5= 74ff490cbca846a66ff0061a5096458e.

[12] F. J. Angulo and K. Molbak, "Human health consequences of antimicrobial drug--resistant Salmonella and other foodborne pathogens," Clinical Infectious Diseases, vol. 41, no. 11, pp. 1613-1620, 2005.

[13] J. Docquier and S. Mangani, "An update on $\beta$-lactamase inhibitor discovery and development," Drug Resistance Updates, Elsevier, vol. 36, , pp. 13-29, 2018.

[14] G. Benjelloun Touimi, L. Bennani, S. Berrada, B. Moussa, and B. Bennani, "Prevalence and antibiotic resistance profiles of Staphylococcus sp. isolated from food, food contact surfaces and food handlers in a Moroccan hospital kitchen," Letters in Applied Microbiology, vol. 70, no. 4, pp. 241-251, 2020.

[15] G. M. Evancho, W. H. Sveum, L. J. Moberg, and J. F. Frank, "Microbiological monitoring of the food processing environment," in Compendium of Methods for The Microbiological Examination of Foods, American Public Health Association, 2nd edition, 2001.

[16] A. W. Paton and J. C. Paton, "Detection and characterization of shiga ToxigenicEscherichia coli by using multiplex PCR 
assays forstx 1, stx 2,eaeA, enterohemorrhagic E. coli hlyA,rfb O111, andrfb O157," Journal of Clinical Microbiology, vol. 36, no. 2, pp. 598-602, 1998.

[17] V. P. Gannon, S. D’Souza, T. Graham, R. K. King, K. Rahn, and S. Read, "Use of the flagellar H7 gene as a target in multiplex PCR assays and improved specificity in identification of enterohemorrhagic Escherichia coli strains," Journal of Clinical Microbiology, vol. 35, no. 3, pp. 656-662, 1997.

[18] EUCAST, "European committee on antimicrobial susceptibility testing," Comité de l'Antibiogramme de la Société Française de Microbiologie, pp. 52-60, 2017.

[19] L. Drieux, F. Brossier, W. Sougakoff, and V. Jarlier, "Phenotypic detection of extended-spectrum $\beta$-lactamase production in enterobacteriaceae: review and bench guide," Clinical Microbiology and Infection, vol. 14, pp. 90-103, 2008.

[20] W. Song, S. G. Hong, D. Yong et al., "Combined use of the modified hodge test and carbapenemase inhibition test for detection of carbapenemase-producing enterobacteriaceae and metallo- $\beta$-Lactamase-producing Pseudomonas spp." Annals of Laboratory Medicine, vol. 35, no. 2, p. 212, 2015.

[21] V. Ntuli, P. M. K. Njage, and E. M. Buys, "Extended-spectrum $\beta$-lactamase, shigatoxin and haemolysis capacity of O157 and non-O157 E. coli serotypes from producer-distributor bulk milk," International Dairy Journal, vol. 66, pp. 126-134, 2017.

[22] C. A. Kennedy, C. Walsh, M. Karczmarczyk et al., "Multi-drug resistant Escherichia coli in diarrhoeagenic foals: pulsotyping, phylotyping, serotyping, antibiotic resistance and virulence profiling," Veterinary microbiology, vol. 223, pp. 144-152, 2018.

[23] S. H. Ryu, J. H. Lee, S. H. Park et al., "Antimicrobial resistance profiles among Escherichia coli strains isolated from commercial and cooked foods," International Journal of Food Microbiology, vol. 159, pp. 263-266, 2012.

[24] A. Lalak, D. Wasyl, M. Zając et al., "Mechanisms of cephalosporin resistance in indicator Escherichia coli isolated from food animals," Veterinary Microbiology, vol. 194, pp. 69-73, 2016.

[25] WHO, Enterohaemorrhagic Escherichia coli in Raw Beef And Beef Products: Approaches for the Provision of Scientific Advice, WHO, Geneva, Switzerland, 2011.

[26] A. Hiko, D. Asrat, and G. Zewde, "Occurrence of Escherichia coli O157: H7 in retail raw meat products in Ethiopia," Journal of Infection in Developing Countries, vol. 2, pp. 389-393, 2008, http:// www.embase.com/search/results?subaction=viewrecord\&from= export\&id=L355909064\%5Cnhttp://sfx.hul.harvard.edu/sfx_local? sid=EMBASE\&issn=19722680\&id=doi:\&atitle=Occurrence + of + Escherichia+coli+O157\%3AH7+in+retail+raw+meat+products+ in+Ethiopia.\&stitle $=\mathrm{J}+$.

[27] E. Gutiérrez-rodríguez, A. Gundersen, A. Sbodio, S. Koike, and T. V. Suslow, "Evaluation of post-contamination survival and persistence of applied attenuated E . coli O157: H7 and naturally-contaminating E. coli $\mathrm{O} 157$ : $\mathrm{H} 7$ on spinach under field conditions and following postharvest handling," Food microbiology, vol. 77, pp. 173-184, 2019.

[28] S. Pieniz, D. F. Rodrigues, R. M. Arndt et al., "Molecular identification and microbiological evaluation of isolates from equipments and food contact surfaces in a hospital food and nutrition unit," Brazilian Journal of Biology, vol. 79, no. 2, pp. 191-200, 2019.

[29] J. M. Gonçalves, K. L. Rodrigues, F. Demoliner, R. Rossales, A. T. S. Almeida, and M. R. D. Buchweitz, "Hygienic and sanitary conditions in the hospital foodservice: relationship between good practices and microbiological quality," Journal of Food Safety, vol. 33, no. 4, pp. 418-422, 2013.
[30] G. Sharma, S. Sharma, P. Sharma et al., "Escherichia colibiofilm: development and therapeutic strategies," Journal of Applied Microbiology, vol. 121, no. 2, pp. 309-319, 2016.

[31] G. B. Touimi, L. Bennani, S. Berrada, M. Benboubker, and B. Bennani, "Evaluation of hygienic conditions of food contact surfaces in a hospital kitchen in Morocco," Iranian Journal of Microbiology, vol. 11, no. 6, pp. 527-534, 2019.

[32] Z. Ma, E. W. Bumunang, K. Stanford, X. Bie, Y. D. Niu, and T. A. McAllister, "Biofilm formation by shiga toxin-producing Escherichia coli on stainless steel coupons as affected by temperature and incubation time," Microorganisms, vol. 7, 2019.

[33] K. C. Klontz, B. Timbo, S. Fein, and A. Levy, "Prevalence of selected food consumption and preparation behaviors associated with increased risks of food-borne disease," Journal of Food Protection, vol. 58, no. 8, pp. 927-930, 1995.

[34] H. Allam, M. Al-Batanony, A. Seif, and E. Awad, "Hand contamination among food handlers," British Microbiology Research Journal, vol. 13, no. 5, pp. 1-8, 2016.

[35] S. L. Tan, H. Y. Lee, and N. A. Mahyudin, "Antimicrobial resistance of Escherichia coli and Staphylococcus aureus isolated from food handler's hands," Food Control, vol. 44, pp. 203-207, 2014.

[36] A. A. Lambrechts, I. S. Human, J. H. Doughari, and J. F. R. Lues, "Bacterial contamination of the hands of food handlers as indicator of hand washing efficacy in some convenient food industries," Pakistan J Med Sci, vol. 30, pp. 755-758, 2014.

[37] E. C. D. Todd, J. D. Greig, C. A. Bartleson, and B. S. Michaels, "Outbreaks where food workers have been implicated in the spread of foodborne disease. Part 3. Factors contributing to outbreaks and description of outbreak categories," Journal of Food Protection, vol. 70, no. 9, pp. 2199-2217, 2007.

[38] R. Garayoa, C. Abundancia, M. Díez-Leturia, and A. I. Vitas, "Essential tools for food safety surveillance in catering services: on-site inspections and control of high risk crosscontamination surfaces," Food Control, vol. 75, pp. 48-54, 2017.

[39] H. Shojaei, J. Shooshtaripoor, and M. Amiri, "Efficacy of simple hand-washing in reduction of microbial hand contamination of Iranian food handlers," Food Research International, vol. 39, no. 5, pp. 525-529, 2006.

[40] S. Badri, A. Fassouane, I. Filliol, M. Hassar, and N. Cohen, "Sequence analysis of the gene encoding $\mathrm{H}$ antigen in Escherichia coli isolated from food in Morocco," The Journal of Microbiology, vol. 48, no. 2, pp. 184-187, 2010.

[41] F. Wang, Q. Yang, J. A. Kase et al., "Current trends in detecting non-O157 shiga toxin - producing Escherichia coli in food," Foodborne Pathogens and Disease, vol. 10, pp. 1-11, 2013.

[42] B. Oporto, J. I. Esteban, G. Aduriz, R. A. Juste, and A. Hurtado, "Escherichia coli O157: H7 and non-O157 Shiga toxin-producing E. coli in healthy cattle, sheep and swine herds in Northern Spain," Zoonoses and Public Health, vol. 55, no. 2, pp. 73-81, 2008.

[43] N. Rahmatallah, S. Nassik, H. E. L. Rhaffouli, I. L. Amine, and M. E. L. Houadfi, "Détection de souches multi-résistantes d' Escherichia coli d'origine aviaire dans la région de Rabat-SaléZemmour-Zaer," Revue Marocaine des Sciences Agronomiques et Vétérinaires, vol. 1, pp. 96-102, 2016.

[44] N. Rahmatallah, H. El Rhaffouli, I. L. Amine, O. F. Fihri, and M. El Houadfi, "Original article consumption of antibacterial molecules in broiler production in Morocco," vol. 4, no. 2, pp. 80-90, 2018. 
[45] E. Skippington and M. A. Ragan, "Lateral genetic transfer and the construction of genetic exchange communities," FEMS Microbiology Reviews, vol. 35, no. 5, pp. 707-735, 2011.

[46] M. J. Day, K. L. Hopkins, D. W. Wareham et al., "Extendedspectrum $\beta$-lactamase-producing Escherichia coli in humanderived and foodchain-derived samples from England, Wales, and Scotland: an epidemiological surveillance and typing study," The Lancet Infectious Diseases, vol. 19, no. 12, pp. 1325-1335, 2019.

[47] N. O. Eltai, H. M. Yassine, A. A. Al Thani et al., "Prevalence of antibiotic resistant Escherichia coli isolates from fecal samples of food handlers in Qatar," Antimicrobial Resistance \& Infection Control, vol. 7, pp. 1-7, 2018.

[48] J. A. Hudson, L. J. Frewer, G. Jones, P. A. Brereton, M. J. Whittingham, and G. Stewart, "The agri-food chain and antimicrobial resistance: a review," Trends in Food Science \& Technology, vol. 69, pp. 131-147, 2017.

[49] S. Schwarz and E. Chaslus-Dancla, "Use of antimicrobials in veterinary medicine and mechanisms of resistance," Veterinary Research, vol. 32, no. 3-4, pp. 201-225, 2001.

[50] K.-F. Kong, L. Schneper, and K. Mathee, "Beta-lactam antibiotics: from antibiosis to resistance and bacteriology," Acta Pathol Microbiol Immunol Scand, vol. 118, pp. 1-36, 2011.

[51] S. P. Kuralayanapalya, S. S. Patil, S. Hamsapriya, R. Shinduja, P. Roy, and R. G. Amachawadi, "Prevalence of extendedspectrum beta-lactamase producing bacteria from animal origin: A systematic review and meta-analysis report from India," PLoS One, vol. 14, pp. 1-15, 2019.

[52] A. Kaesbohrer, K. Bakran-lebl, A. Irrgang et al., "Diversity in prevalence and characteristics of ESBL/pAmpC producing E. coli in food in Germany," Veterinary Microbiology, vol. 233, pp. 52-60, 2019.

[53] S. Sapkota, S. Adhikari, S. Khadka et al., "Multi-drug resistant extended-spectrum beta-lactamase producing E. coli and Salmonella on raw vegetable salads served at hotels and restaurants in Bharatpur, Nepal," BMC Research Notes, vol. 12, pp. 1-6, 2019.

[54] World Health Organization \& WHO Advisory Group on Integrated Surveillance of Antimicrobial Resistance (AGISAR)., "Critically important antimicrobials for human medicine: ranking of antimicrobial agents for risk management of antimicrobial resistance due to non-human use. 5th rev. World Health Organization," 2017, https://apps.who.int/ iris/handle/10665/255027.

[55] A. Irrgang, B. A. Tenhagen, N. Pauly, S. Schmoger, A. Kaesbohrer, and J. A. Hammerl, "Characterization of VIM-1-producing E. coli isolated from a German fattening pig farm by an improved isolation procedure," Frontiers in Microbiology, vol. 10, pp. 1-11, 2019. 